\title{
El concepto de España en Didáctica de las Ciencias Sociales
}

\section{Javier Cermeño Aparicio}

Arbor CLXXIII, 681 (Septiembre 2002), 183-201 pp.

Son numerosos los estudios sobre la enseñanza de la Historia en los ss. XIX y XX, a partir de los libros de texto utilizados por los alumnos de Primaria y de Secundaria, pero es necesario también realizar estudios parciales sobre el aprendizaje de algunos conceptos clave, como el concepto de España. Frente a la idea de España dominante desde comienzos del s. XIX, otras ideas han tardado en imponerse o no lo han conseguido nunca del todo, como, por ejemplo, la de la Institución Libre de Enseñanza y la de Menéndez Pelayo. Ningún concepto de España enseñado en nuestras Escuelas, Institutos y Colegios alcanzó nunca un consenso duradero y estable, lo cual puede ser considerado como un fracaso histórico de la Escuela. Algo semejante sucede en la actualidad, y la consecuencia es el debilitamiento del sentimiento patriótico entre los españoles. Por eso, hoy más que nunca, en nuestro sistema educativo es necesario formular un concepto de España que pueda servir a los españoles del mañana para cimentar los necesarios lazos afectivos con la patria común de todos ellos. Si la Escuela no lo hace, otros, con diferentes propósitos, lo harán.

La investigación en Didáctica de las Ciencias Sociales se ha orientado con frecuencia a estudiar cómo han sido enseñadas en España, a lo largo de los siglos XIX y XX, algunas disciplinas fundamentales, en los niveles de Enseñanza Primaria y Secundaria. Aunque también se han te- 
nido en cuenta las informaciones proporcionadas por escritores, políticos y educadores, las fuentes documentales generalmente utilizadas para la realización de estos trabajos han sido los libros de texto manejados por los alumnos en las Escuelas de Enseñanza Primaria y en los Institutos de Bachillerato. Y ello, porque, como es sabido, el libro de texto ha tenido durante mucho tiempo una importancia capital, cuando no un protagonismo casi exclusivo, en la transmisión de conocimientos a los alumnos de esos niveles educativos.

La importancia de estas investigaciones puede destacarse desde una doble perspectiva: desde el marco general de la Historia de la Educación y desde el campo concreto de la Didáctica de las Ciencias Sociales. Para la Historia de la Educación en España, e incluso para una más amplia Historia de la Cultura, es evidente el significado que tienen los libros de texto, ya sean considerados como objetos culturales valiosos por sí mismos o como medios para la transmisión del saber y de la cultura vigentes en una sociedad, en un momento determinado de su desarrollo histórico. De igual manera, para la Didáctica de las Ciencias Sociales, analizar los métodos utilizados en la enseñanza de disciplinas como la Geografía, la Historia y la Historia del Arte, destacar las variaciones experimentadas en los sistemas de enseñanza de esas materias; comprobar los resultados obtenidos en cada momento; todo ello, además de valioso para el conocimiento del pasado, proporciona, entre otras cosas, una información necesaria para detectar problemas actuales en la enseñanza y aprendizaje de esas disciplinas, para consagrar o desechar principios metodológicos, para superar errores o insuficiencias y, en definitiva, para facilitar la tarea a cuantos profesores se esfuerzan hoy por mejorar la calidad de sus enseñanzas.

En este sentido, el interés por la enseñanza de la Historia durante los dos últimos siglos también se ha puesto de relieve mediante la realización de numerosos trabajos basados en el análisis de los libros de texto, la mayoría orientados a la elaboración y presentación de tesis doctorales. Cuando se trata de trabajos sobre la enseñanza de la Historia en general, se suele subrayar la diferencia existente entre considerar la Historia como una materia fundamental para la formación de los alumnos -y, por lo tanto, la tendencia a destacar su carácter formativo y la necesidad de impartirla de manera «objetiva», o por lo menos «imparcial»- y considerar la Historia como igualmente fundamental para la transmisión de principios ideológicos al servicio de determinados intereses sociales, económicos y políticos $-\mathrm{y}$, en consecuencia, la tendencia a destacar su carácter doctrinal, lo que lleva a la manipulación de sus contenidos-. Es evidente que no resulta fácil establecer con nitidez la línea que separa 


\section{El concepto de España en Didáctica}

ambos planteamientos, y podría decirse que, en conjunto, la enseñanza de la Historia siempre ha participado indistintamente de ambas tendencias, si bien con matices importantes según las épocas. No obstante, y aunque sea a nivel teórico, la distinción entre una "Historia que educa» y una «Historia que manipula» puede aceptarse como punto de partida, por cuanto ayuda a delimitar el campo de la investigación y a definir con precisión algunos conceptos.

Este planteamiento también se pone de relieve cuando se trata de trabajos sobre la enseñanza de la Historia de España. Los estados liberales que fueron constituyéndose a lo largo del s. XIX -y España no es una excepción- tuvieron desde sus comienzos la convicción de que la enseñanza de la Historia nacional no importaba sólo por su aportación esencial, concreta y no discutida, a la formación del individuo -cosa, por otra parte, común a otras muchas disciplinas-, sino que también era fundamental para la educación del ciudadano, soporte del nuevo estado en construcción. Educar para la convivencia en un sistema de libertades crecientes, vincular al ciudadano con la nueva realidad estatal, imbuirle de un renovado sentimiento de amor a la patria -a su vez renovada en sus estructuras, pero «esencialmente» perdurable-, eran otras tantas tareas prioritarias si se quería consolidar el Estado liberal. La educación, en general, y la enseñanza de la Historia nacional, en particular, tuvieron desde ese momento un valor añadido y un especial significado. Pero si la enseñanza de la Historia fue utilizada entonces al servicio del proceso de formación ideológica del ciudadano, nada debe extrañar que, en algunas ocasiones, la Historia haya sido analizada después como si únicamente se tratara de una modalidad más de transmisión del pensamiento desde una minoría dominante hacia las clases populares, o incluso como una simple técnica de propaganda al servicio de los «poderes establecidos».

\section{El concepto de España en la educación}

Sin negar la importancia de los trabajos realizados sobre la enseñanza de las distintas disciplinas sociales, y en especial de la Historia, en los dos últimos siglos, y sin abandonar la doble perspectiva antes mencionada de una "Historia que educa» frente a una "Historia que manipula», la investigación sobre la enseñanza de la Historia de España puede ampliar su campo de actuación, si se orienta al estudio de la transmisión de algunos conceptos clave a lo largo del tiempo y en los diferentes niveles educativos. Es decir, si se vuelve la vista desde los planteamientos generales a los aspectos concretos, analizando cómo se han enseñado deter- 
minados conceptos, cómo han sido asimilados y hasta qué punto han alcanzado un carácter «operativo». Los estudios parciales de conceptos como «liberalismo», «democracia», «regionalismo», «nación», «nacionalismo» y «patria», por no poner sino unos cuantos ejemplos, permitirían profundizar en el conocimiento de los temas y facilitarían la posterior realización de síntesis más elaboradas.

En estos casos, no se trataría de analizar la metodología utilizada -por lo que su interés para la Historia de la Educación o para el conocimiento de la enseñanza de la Historia como ciencia social sería menor-, sino más bien de aclarar los significados que se han dado a los distintos conceptos y cómo esos significados han influido, y en qué medida, sobre los individuos y los grupos sociales. Un aspecto que interesa tanto desde las perspectivas ideológicas y educativas, como desde las sociológicas y políticas.

Además, y aunque sea algo marginal al tema que nos ocupa, analizando algunos conceptos históricos clave y cómo han sido transmitidos por los libros de texto en las diferentes etapas de los siglos XIX y XX, no solo se atendería al estudio de un problema educativo perteneciente al campo específico de la enseñanza de la Historia, sino que se contribuiría al estudio de un aspecto general que hoy sigue planteando problemas, a veces muy graves, en todos los niveles educativos, pero cuyas raíces se encuentran en la Enseñanza Primaria y, sobre todo, en la Enseñanza Secundaria: la deficiente conceptuación por parte de los alumnos, la imprecisión -cuando no el error-en la utilización de los conceptos, la tergiversación de lo que deberían ser conceptos claros sobre los que se pudieran edificar los futuros y sucesivos saberes, en lugar de incongruencias y vaguedades.

Uno de estos conceptos fundamentales con el que nos encontramos al afrontar la enseñanza de la Historia nacional es el mismo concepto de España. La idea, o más bien las ideas que de España se han tenido -y, por lo tanto, las que se han enseñado- son muchas y variadas. La realidad de España como entidad histórica; su desarrollo temporal y las modificaciones que ha tenido en su propia naturaleza histórica a través de los siglos; las distintas manifestaciones o modalidades que ha adoptado en el curso de la historia; es decir, para unos, lo que España «es», su «esencia», su personalidad como objeto de estudio histórico; para otros, lo que «ha sido» en cada época según se ha ido constituyendo históricamente; y para otros, lo que «ha llegado a ser» después de su larga trayectoria existencial. Todo esto ha dado, en numerosas ocasiones, motivo a debates interminables entre historiadores y a polémicas apasionadas entre intelectuales y políticos, y ha llegado a formar parte del acervo histórico y 
cultural del pueblo español. «¿Qué es España?» ha sido una de las preguntas más repetidas en nuestra historiografía, y sus ecos perduran en la actualidad. Y ello porque, como queda dicho, las respuestas a esa pregunta han sido muchas y variadas, pero, al parecer, nunca lo suficientemente convincentes como para que dejáramos de repetir la pregunta. El caudal de opiniones al respecto ha enriquecido nuestro patrimonio histórico y cultural, iluminando importantes aspectos de nuestro pasado, pero no se ha logrado alcanzar un consenso capaz de superar la preocupación que expresamos cada vez que nos preguntamos «¿qué es España?».

Si el concepto de España ha planteado problemas en el pasado -cuando se trataba de «traducir» ese concepto en la práctica política o constitucional, definiendo la nación española y sus estructuras representativas o administrativas-, también los plantea hoy. La discusión sobre lo que España sea lleva siempre a la formulación de distintos modelos de Estado y diferentes sistemas de organización territorial, todos ellos con la pretensión de ser los más adecuados para dar cabal expresión actualizada de lo que España «es», o de lo que «ha sido» en su historia, o de lo que «ha llegado a ser» en el momento presente.

Se trata, pues, de un tema con resonancias en el pasado y en el presente; con matices que se refieren a la enseñanza de los conceptos y a la enseñanza de la Historia de España; con implicaciones que van de lo ideológico a lo político y social; y con consecuencias, en fin, que afectan al entendimiento de nuestra convivencia como españoles, en el pasado más reciente, en la actualidad y en el inmediato futuro. Tan pertinente y necesario es investigar qué idea o ideas de España han sido transmitidas -y con qué consecuencias- en las Enseñanzas Primaria y Secundaria del pasado, como preguntarnos qué concepto o conceptos de España estamos enseñando hoy a nuestros alumnos y cuáles pueden ser las consecuencias futuras. Porque hoy sigue preocupando este tema. Porque seguimos planteándonos qué idea de España debemos enseñar, en nuestras Escuelas e Institutos, que sea «operativa» el día de mañana y capaz de asegurar la permanencia futura de España como nación y la convivencia pacífica de los españoles. Y esto es algo que preocupa tanto a los educadores como a los intelectuales en general y a los políticos, según hemos tenido ocasión de comprobar no hace mucho con la polémica desatada por la llamada «Reforma de la enseñanza de las Humanidades», o por la muy reciente difusión de la opinión de algunos miembros del Gobierno, expresando la necesidad de generalizar entre los españoles el llamado "patriotismo constitucional».

También en este caso, como en otros muchos proyectos anteriores de nuestra historia reciente, se trataría de consolidar una idea de España 
de carácter «operativo», es decir, que tuviera como consecuencia la vinculación a determinada forma de patriotismo o a una manera específica de entender el patriotismo, por más que este concepto parezca estar desprestigiado en la actualidad. Si España es una realidad «esencial», se. afirmará esa realidad; si es una «fe», se creerá en ella; si es un «sueño», se confiará en hacerlo realidad. Lo que no está tan claro es qué tipo de sentimiento o de razonamiento patriótico puede ligar a los españoles con la patria mediante el «patriotismo constitucional», porque el «patriotismo», como la «democracia», cuando está acompañado de un adjetivo, no resulta ampliado en su práctica, sino limitado.

\section{Las visiones sobre el concepto de España}

Es evidente que si la idea de España ha suscitado diferentes interpretaciones entre los historiadores, escritores, políticos e intelectuales en general, es el reflejo de su pensamiento lo que ha llegado a la Escuela. Fundamentalmente a través de los libros de texto, los niños y adolescentes han aprendido un determinado concepto de España, aquél que en cada situación política o en cada época estaba en vigor, tanto si era la idea de España aceptada por la mayoría de los historiadores, como si solo era la idea compartida por la minoría dominante. Tanto si era ciencia "puesta al día», como si era ideología "puesta a interés». Pero en cualquier caso, un análisis del tratamiento que los libros de texto han dado al concepto de España en los dos últimos siglos no puede realizarse sin tener en cuenta esas interpretaciones. No se puede buscar el reflejo, la síntesis o la simplificación de una idea en un libro de texto, si antes no se conoce la fuente de donde procede. Como no se puede afirmar la influencia de un pensamiento o de un autor, sin conocerlos a fondo. Lo contrario sería volver a la repetición de tópicos, cosa que en este tema ha sido más frecuente de lo deseable.

Se impone, por lo tanto, -para poder afrontar este trabajo con algunas garantías de éxito-, una toma de contacto con la abundante bibliografía que sobre la idea de España se ha producido en los últimos doscientos años, lo que representa, sin duda, una ardua tarea. Conocer las visiones antes de empezar a analizar los libros de texto es algo que parece imprescindible, pero que no siempre se ha hecho con rigor y profundidad.

Sin sobrepasar los límites cronológicos del s. XIX, podrían destacarse tres corrientes historiográficas que se ocuparon ampliamente de este tema. La primera, la que podríamos denominar «corriente tradicional», 
hunde sus raíces en el pensamiento ilustrado, o incluso en el de los ss. XVI y XVII. Aunque fue considerablemente modificada por el liberalismo, muchos de sus principios se mantuvieron vigentes. Se manifestó con fuerza a partir de la Guerra de la Independencia, y, con los nuevos aportes liberales, alcanzó su definitiva formulación en la monumental Historia de España, de Modesto Lafuente, escrita por éste hasta su muerte, en 1866, y continuada por Juan Valera, con la colaboración de Andrés Borrego y Antonio Pirala, hasta 1905. La segunda, de la que hablaremos más adelante, está representada por la Institución Libre de Enseñanza. Y la tercera, la conservadora, fue iniciada por Menéndez Pelayo entre 1876 («Polémica de la Ciencia española») y 1881 («Brindis del Retiro»), aunque sus aspectos más significativos quedaron recogidos en su Historia de los heterodoxos españoles, obra publicada entre 1880 y 1882.

Es probable que, al buscar el reflejo de esas teorías en los libros de texto de Enseñanza Primaria y Secundaria, nos encontremos con una realidad ya presentida: su influencia es a veces débil y casi siempre tardía. Porque la Escuela es un mundo de inercias. Porque las ideas nuevas no llegan a la Escuela sino después de mucho tiempo. Porque los libros de texto repiten las mismas cosas año tras año y ellos mismos se mantienen en uso durante décadas, sin renovarse y sin ser sustituidos por otros nuevos. Pasan de mano en mano, de hermano en hermano, a veces de generación en generación, impasibles ante las innovaciones conceptuales y metodológicas, como si los conocimientos y las ideas que transmiten estuvieran consagrados por el tiempo y petrificados.

Ese es el caso de la corriente historiográfica tradicional. Desde comienzos del s. XIX recogió tendencias ya manifestadas con anterioridad, las enlazó con unos cuantos principios nuevos y formuló algunas ideas sobre el «ser» de España que han venido repitiéndose casi sin interrupción hasta muy avanzado el S. XX. España era una de las naciones más antigua del mundo, el carácter y la personalidad del pueblo español mostraban ya sus rasgos más peculiares desde época prerromana y la "esencia» de España había permanecido invariable en el transcurso de los siglos. La Guerra de la Independencia había sido la coyuntura propicia para reafirmar el sentimiento de amor a la patria y para realizar la más heroica defensa de unos valores espirituales compartidos por el pueblo, aunque no siempre bien entendidos y protegidos por una Monarquía Absoluta, a la que ahora se pretendía sustituir por un nuevo Estado Liberal, más en consonancia con nuestras auténticas tradiciones culturales y populares. Las Cortes de Cádiz procedían a renovar el concepto mismo de nación, de acuerdo con las últimas aportaciones del pensamiento político y nacionalista europeo, con lo que España, siempre existente y siem- 
pre fiel a sí misma, pasaba ahora a ser una verdadera «nación», por obra del nuevo Estado Liberal triunfante.

En el fondo, se trataba de la actualización de concepciones en vigor desde finales de la Edad Media y comienzos del Renacimiento, porque la idea que subyace en esta interpretación, largamente enseñada en nuestras Escuelas e Institutos, enlaza el moderno concepto de nación con el de la «entidad político-espacial diferenciada» (utilizaré provisionalmente esa denominación a falta de otra mejor), que parecía consagrado por la historia y que hasta el s. XVIII podría formularse así: una «entidad político-espacial diferenciada» es una realidad «de hecho» en un momento dado, una realidad perteneciente al mundo de las relaciones internacionales y con lo que hay que contar, porque existe como tal y como tal es aceptada por la comunidad internacional. La nación, a partir de la Revolución Francesa, podrá basarse, además de en consideraciones de unidad política y territorial, en criterios espirituales, lingüísticos, culturales, raciales o históricos, pero si no obtiene el reconocimiento internacional, no será una nación en sentido pleno. Será un «proyecto de nación», un «conato de nación», pero sin capacidad para lograr el reconocimiento internacional acabará por ser inviable. Y la demostración de la viabilidad de una nación, como antes la de una «entidad político-espacial diferenciada», es su capacidad para perdurar en el tiempo. Es decir, una nación parte de una realidad «de hecho» que perdura en el tiempo. Una nación es el resultado de un proceso en el tiempo, en el que la existencia es anterior a cualquier otra justificación filosófica o jurídica.

Es por eso que los españoles no siempre ven su realidad nacional y los extranjeros la perciben con nitidez. Los españoles dudamos de los lazos que nos unen, cuando el resto de los europeos los afirma sin vacilar, aunque pueda parecer una paradoja que la perspectiva internacional caracterice y consolide a las naciones con menos vacilaciones que la perspectiva nacional. $\mathrm{Y}$ es que definir la nación a partir de los principios establecidos en los últimos años del s. XVIII y los primeros años del s. XIX, es decir, de acuerdo con las teorías elaboradas por Herder, la filosofía alemana, los románticos y los ideólogos del nacionalismo decimonónico, para después afirmar que tal realidad, así definida, no existía en épocas anteriores, es obvio. Pero argumentar que España no existía como «entidad político-espacial» antes del s. XIX, porque todavía no había sido definido el concepto moderno de nación, es tanto como afirmar que el concepto es previo a la realidad. En este caso, el concepto nación no vendría a denominar, definir y explicar por sus componentes una realidad previamente existente, sino más bien a crearla, como se ha afirmado en no pocas ocasiones (Fox 1997). 
Estas ideas, con otras semejantes que de ellas derivan, han venido repitiéndose sin cesar y han sido absolutamente hegemónicas en nuestras Escuelas e Institutos, con independencia de las situaciones políticas por las que atravesase el país. Frente a ellas, otras interpretaciones que se irán produciendo tardarán en imponerse y no siempre lo harán del todo, aspecto este que no conviene pasar por alto. En su mayoría, se trataba de «visiones» tan diferentes acerca de la realidad de España, que resultaban imposibles de conciliar. En lugar de contribuir al establecimiento de un concepto de España al servicio de la unidad y la paz social, acabaron por contribuir a la discrepancia y el enfrentamiento, haciendo aún más difícil la instalación de un sentimiento patriótico común. A modo de ejemplo, nos detendremos en dos de esas interpretaciones absolutamente contrapuestas, cuya influencia se dejó sentir en buena parte del pasado siglo.

\section{El concepto de España y la Institución Libre de Enseñanza}

Hemos dicho que la Escuela es un mundo de inercias. Pero a veces en la Escuela hay cambios y se introducen nuevos saberes o nuevas interpretaciones de la realidad, aunque siempre sea con lentitud, con moderación y, sobre todo, siempre de forma tardía.

Este es el caso de la idea de España expresada por los hombres de la Institución Libre de Enseñanza (ILE). Se fue plasmando a partir de las respuestas dadas a dos cuestiones básicas sobre el pasado español entendido como problema, planteamiento este compartido por la mayoría de los miembros de la Institución y por muchos otros que, durante varias generaciones, fueron influidos, de una forma u otra, por las ideas institucionistas y, sobre todo, por las ideas y la personalidad de Francisco Giner de los Ríos.

La primera de esas cuestiones problemáticas, la preocupación por la llamada «cuestión religiosa», estuvo marcada desde sus comienzos por la «visión tétrica del cristianismo», característica de Giner de los Ríos. La segunda, la preocupación por la llamada «decadencia española», produjo todo un subgénero literario de carácter histórico, cuyos ecos no se han dejado de oír hasta hoy. Ambas fueron ocasión para la polémica, los duros enfrentamientos dialécticos y la radicalización ideológica, dando origen a opiniones sobre el pasado y actitudes hacia el futuro, que acabaron demostrándose como difícilmente conciliables.

La preocupación por el pasado histórico de España, unida a un sentimiento de «amor dolorido" por el presente de la nación y a la aceptación de la responsabilidad respecto a un futuro siempre incierto, llevó a Giner 
y a sus seguidores a la formulación de las teorías sobre el «complejo de frustración» nacional, fruto, en su opinión, de un cierto «desviacionismo histórico» manifestado en el desarrollo temporal de la nación española. Todo ello desembocó en una larga decadencia, cuyos responsables fueron los representantes de la España «castrense y frailuna» dominantes mientras se mantuvo en el poder la dinastía de los Habsburgo, que hicieron discurrir la Historia de España por caminos errados. La Historia de España «oficial» $\mathrm{y}$ «aparente» de los tiempos modernos no fue sino la historia de una frustración y de una decadencia, porque la pérdida del sentido auténtico y profundo de lo que España «podía haber llegado a ser» y la imposición de principios e ideales equivocados tuvo como resultado una historia desdichada y negativa. Esto nos impidió el progreso, nos distanció del resto de los países europeos y nos apartó de la verdadera modernidad.

Semejante visión de nuestra historia no podía sino provocar el rechazo más absoluto de esa misma historia. Y ello, -el rechazo del pasado de España visto en negativo, como la historia de una decadencia sin fin-les llevó a buscar la auténtica realidad de España en lo que entonces se llamó la «subhistoria» o «intrahistoria»: la que latía y corría por debajo de las apariencias; la que mejor expresaba nuestras posibilidades como nación civilizada; la que había sido soterrada y ocultada por los "poderes oficiales» al servicio de ideales equivocados; la que, en fin, se correspondía mejor con nuestra personalidad psicológica y cultural, con nuestra realidad más auténtica, profunda y esencial de españoles.

Los hombres de la ILE defendían una modalidad de Historia más ideológica que positivista, al menos en la llamada primera generación, la de Giner y sus más directos colaboradores. En ella, la «razón» se imponía a la «vida» y el «pensamiento» al «ser». Negar «lo que fue» nuestra historia real, acudiendo al recurso «intrahistórico» para buscar por debajo de la realidad «lo que pudo ser», quizás demostraba, como afirmó Laín Entralgo (1962), «un deliberado desconocimiento de lo que nuestra historia fue», pero al menos les permitió enfrentarse a la mediocre realidad que les abrumaba y soñar con un futuro diferente para España, un futuro de progreso y de convivencia pacífica a la altura de los tiempos y en consonancia con los valores dominantes en los países de nuestro entorno.

Como dice Gómez Molleda (1966), quisieron «proporcionar las bases doctrinales para una teoría de la Historia de España», aunque fuera a costa de «intelectualizar todos los tópicos» que sobre nuestra decadencia se han venido repitiendo desde entonces. Aceptaron la diferencia establecida por Krause entre una «Historia externa» y otra «interna», para afirmar los valores «subhistóricos» representativos del «espíritu del pue- 
blo» y ahondar en la «psicología específica del español», aunque fuera a costa de negar los «valores tradicionales -entre ellos y sobre todo, los valores del catolicismo-.

En su intento de hacer una Historia más filosófica y psicológica, acabaron negando los aspectos temporales y evolutivos de la Historia, sin los cuales es imposible hacer verdadera ciencia histórica. Su rechazo de «lo que fue» en favor de «lo que pudo ser» demostraba, en definitiva, tanto su idealismo casi utópico como su escasa sensibilidad histórica. La España soñada de Giner, la que no fue, y su desprecio por la España real del pasado y del presente, les impulsaba a trabajar por una España diferente para el futuro.

Frente a esa visión negadora del pasado y afirmadora del futuro, otros, como Menéndez Pelayo, no tardaron en oponer una visión contraria, basada en la esperanza de que la España que fue -en este caso la del catolicismo y la tradición- pudiera seguir siendo en el futuro. Y ello, porque en los hombres de la ILE el rechazo del pasado español iba unido al rechazo total de lo que ellos denominaban el «catolicismo oficial», al que negaban su condición de elemento fundamental para entender la Historia de España y al que consideraban como un lastre para el progreso y la convivencia pacífica de los españoles. Por eso, su defensa de la necesaria «europeización» de España incluía la secularización como condición imprescindible para ese progreso y esa convivencia, en la convicción de que el catolicismo vigente en aquellos momentos y el excesivo protagonismo de la Iglesia Católica en todos los sectores de la vida nacional contribuían a la intolerancia, la división y los enfrentamientos. Este rechazo del catolicismo -aspecto fundamental de su visión negativa del pasado- dio origen a la llamada «cuestión religiosa», que se planteó sobre todo en el terreno educativo, como es bien sabido.

Un último rasgo distintivo de la idea de España defendida por la ILE es su concepto materialista y «sensorial» de la patria, ligada siempre a los elementos físicos que la componen (tierra, paisaje, cielo, suelo, raza, territorio, etc.), así como a los elementos folklóricos y lingüísticos, que contribuyeron a crear un patriotismo en parte de carácter físico y en parte de carácter literario. La segunda generación de institucionistas, la dé los «científicos», coincidió en muchos aspectos con los hombres de la Generación del 98 y los Regeneracionistas. Rechazaron en parte la Filosofía de la Historia y los criterios historicistas anteriores, cultivando más las metodologías y afirmando su vocación científica y su aceptación del Positivismo. Todos ellos encontraron nuevos motivos de preocupación y algunos hallaron nuevas formas de expresión, pero en conjunto se puede decir que acentuaron ese concepto sensorial y literario de la patria. 
Siguieron aferrados al pasado «que pudo ser» y al consiguiente rechazo de la Historia de España. La mayoría cultivó el ensayismo y cayó en las interpretaciones históricas apresuradas y sin hondura, así como en cierto «relativismo histórico».

También los Regeneracionistas y la Generación del 98 deben muchas de sus ideas a la ILE. Difundieron un anticlericalismo intelectualizado y expresaron su rechazo a la España de los ss. XVI y XVII, pero su mezcla de racionalismo e irracionalismo les llevó a renegar del «catolicismo inquisitorial» y al mismo tiempo a revalorizar a los místicos, como Fray Luis de León. A modo de ejemplo de las influencias institucionistas, se podría mencionar la búsqueda de lo «intrahistórico» y «castizo» en Unamuno; el «europeísmo» de Costa; el paisajismo de casi todos ellos; la valoración de lo psicológico; la desesperanzada visión de España, no exenta de tópicos y en exceso «literaria»; y, en resumidas cuentas, el escaso sentido histórico que demostraron.

En el s. XX, el reformismo educativo de la ILE se hizo político. La «revolución desde abajo» que significaba la Escuela dejó su lugar a la «revolución desde arriba» que significaban la actividad política, la Junta de Ampliación de Estudios y el Ministerio de Instrucción Pública. Vendrían otros tiempos y otras interpretaciones de la realidad española. Y vendrá la II República española, la gran ocasión para que las ideas de la ILE respecto a España pudieran ser enseñadas en nuestras escuelas de manera duradera. No es necesario insistir en que se trató de una ocasión frustrada con demasiada rapidez.

\section{El concepto de España en Menéndez Pelayo}

Para Menéndez Pelayo, la «esencia» de una nación está en su pasado. $\mathrm{Y}$ el deber de la Historia es recuperar ese pasado para preservar la memoria de esa «esencia», configurada en el tiempo, y para garantizar su perduración. Pero como las visiones del pasado pueden ser hijas de muy variadas interpretaciones, y la configuración del presente siempre dependerá de ellas, la Historia no pretende otra cosa que erigirse en «legitimadora de una determinada forma de entender la realidad política, social y económica» (Santoveña 1994). Por ello, la Historia es un medio excepcional para influir en el orden vigente, para conocer los elementos vertebradores de la nación y para asegurar su permanencia en el tiempo. $\mathrm{Y}$ todo esto puede hacerse sin tener que renunciar a determinados «presupuestos ideológicos», que en el caso de España son básicamente dos: la fidelidad a la tradición clásica y la aceptación del catolicismo. Ambos pre- 
supuestos constituyen el substrato fundamental de nuestra cultura y de nuestra existencia como nación.

Es evidente que el sentido providencialista de la Historia y la idea esencialista de España subyacen en esta interpretación. En contra de la opinión romántica y liberal, España como nación no se basa en la unidad de lengua, pues también el catalán, el vasco y el galaico-portugués son lenguas españolas. Ni se basa en la unidad de raza, ya que el pueblo español es fruto del mestizaje. Y tampoco se basa en la unidad cultural, que dejaría al margen las aportaciones árabes y judías. España es, para Menéndez Pelayo, la expresión de un pasado y de un "proyecto común» basados en el Dogma Católico, por lo que en nuestro caso nacionalidad y religión se identifican.

Para Menéndez Pelayo el s. XVI representa la cima de nuestro desarrollo histórico y cultural. Allí se impuso la unidad nacional, la descentralización administrativa, la libertad municipal y foral, y la Monarquía moderada y católica. Su "visión organicista» de España le permitió entender mejor que otros los sentimientos regionalistas de los catalanes y defender el «foralismo instintivo» de regiones y municipios como solución al problema de la unidad nacional. No es extraño que situara el comienzo de nuestra decadencia en el s. XVIII, cuando el espíritu foráneo se impuso a la tradicional manera de pensar y actuar hispana. Ni que considerara el s. XIX como el de la confirmación de esa decadencia, cuando el Absolutismo degenerado de Fernando VII dividió al país en dos conjuntos irreconciliables, la Desamortización arruinó a la Iglesia y la Constitución de 1876 consagró la libertad de cultos. Todo esto era expresión del desprecio por nuestra historia, la aceptación de ideas y principios foráneos, la ruptura con la tradición española y el rechazo de un «tradicionalismo moderno", único capaz de preservar la grandeza y la unidad de España.

Estos planteamientos, no obstante, no le impiden afirmar ideas de evidente raíz romántica, como el carácter racial de la cultura española, producto de una personalidad nacional que ha permanecido invariable en el transcurso del tiempo y que se caracteriza por su sentido práctico y no teórico, típico de una sociedad forjada en una frontera de civilización, en la que predominan los «teólogos armados».

Su catolicismo, unido a su defensa de un modelo de Estado descentralizado, le inspiró el célebre "Brindis del Retiro», con motivo de los actos conmemorativos del Centenario de Calderón de la Barca. Frente a los que renegaban del pasado y del presente católicos de España, frente a los que argumentaban que España estaba por hacerse como nación, y frente a los defensores del centralismo de raíz francesa, quiso sumarse al acto 
brindando por «la fe católica apostólica romana», «por la nación española» y «por el municipio español». Era la expresión, como ya indicó Sáinz Rodríguez (1962), de un patriotismo ligado al pensamiento de Renan, Brunetière, Barrès, Wundt y la psicología de los pueblos, concepciones todas ellas que renacerán en los nacionalismos del s. XX, en la Dictadura de Primo de Rivera y en la época franquista. Fue entonces cuando las ideas de Menéndez Pelayo suscitaron la solidaridad de muchos y alcanzaron su mayor vigencia y su más amplia difusión en el sistema educativo.

\section{El concepto de España en la Escuela, ¿historia de un fracaso?}

Un aspecto que no debiera ser olvidado, a la hora de analizar cómo se han enseñado en la escuela los distintos conceptos de España, se relaciona con el número de alumnos de Enseñanza Primaria y Secundaria que, en los distintos momentos, estaban matriculados en los centros educativos existentes, ya fueran estatales o privados. A lo largo del s. XIX estas cifras se fueron incrementando de manera notable, pero, aún así, a finales de la centuria solo había 1.617.824 alumnos de Primaria, de un total de 2.373.179 niños en edad escolar, y únicamente 45.000 alumnos de Secundaria, de los cuales unos 30.000 asistían a centros privados.

Esto significa que la idea de España transmitida a través del sistema educativo no universitario, sobre todo en Bachillerato, apenas podía llegar a una reducida parte de los futuros ciudadanos españoles. Los estudiantes que después accedían a la Universidad, todavía en número más reducido, entraban a formar parte de otra dimensión educativa y recibían otras influencias muy variadas, en función de la carrera elegida, del ambiente cultural en el que se movieran y de sus propias preocupaciones intelectuales. Y más aún en el caso de las minorías dirigentes o de las elites culturales. En ambos casos, minorías o grupos profesionales de formación universitaria, la idea de España recibida en las Escuelas e Institutos apenas significaría algo más que un punto de partida o idea base, muy modificado luego y por lo tanto poco «operativo» a la hora de generar determinados sentimientos patrióticos.

Los que no recibían ningún tipo de enseñanza y los que apenas iban más allá de unas ligeras nociones de lectura y escritura, o permanecía en la ignorancia o recibían otras influencias posteriores. Cada vez más a través de los sindicatos obreros, a veces de los partidos políticos $\mathrm{y}$, en menor medida, a través de la prensa, la lectura en general y otras manifestaciones culturales, cívicas, sociales y políticas. 
En cualquier caso, unos y otros quedan fuera del tema que nos ocupa, pero, al ser su número tan elevado, constituyen una realidad en absoluto desdeñable, sobre todo cuando se intenta formular conclusiones de carácter general. Porque, si se estudia la idea de España enseñada a nuestros escolares no universitarios durante los últimos doscientos años, es obvio que quedan fuera del estudio los que nunca han formado parte de esos niveles educativos y los que luego los han superado. Pero si se trata de averiguar hasta qué punto la idea de España recibida en las Escuelas e Institutos ha permanecido más o menos estable en las mentes de los alumnos y, en consecuencia, si ha sido una idea "operativa» en nuestra vida social y política, en nuestra convivencia, es preciso no olvidar que un gran número de españoles o no recibió nunca esas enseñanzas o las modificó luego de forma sustancial.

En el s. XX, el número de alumnos de Primaria y Secundaria fue aumentando incesantemente. A partir de los años sesenta del pasado siglo se puede decir que la Enseñanza Primaria Obligatoria alcanzó a la casi totalidad de los niños españoles. En la actualidad, como es sabido, la Enseñanza Secundaria Obligatoria se extiende hasta los 16 años y el número de alumnos escolarizados representa prácticamente el $100 \%$ del total de adolescentes en edad escolar. En nuestras Escuelas estatales, Institutos de Bachillerato y Colegios privados estudian hoy decenas de miles de alumnos.

Hoy más que nunca se puede afirmar que la idea o ideas de España enseñadas a nuestros escolares no universitarios alcanzan a la totalidad de los ciudadanos españoles del futuro, por lo que cualquier esfuerzo que vaya encaminado a conocer esas ideas, precisar sus contornos y prever sus posibles consecuencias no será en vano. En este sentido, la preocupación manifestada por las autoridades políticas, los debates suscitados recientemente y el interés de la prensa por el problema, son otras tantas llamadas de atención sobre la actualidad del tema objeto de estudio.

No obstante, si tenemos en cuenta que la Escuela es un mundo de inercias y la influencia de las teorías suele ser tardía, y si consideramos que hasta muy avanzado el $\mathrm{s}$. XX el número de alumnos de Primaria $\mathrm{y}$, sobre todo, de Secundaria era tan reducido que las ideas recibidas a través de los libros de texto solo podían influir en unos pocos, como hemos indicado previamente, tendríamos que aceptar el fracaso histórico del sistema educativo español, al menos en lo que respecta al intento de transmitir una idea de España que fuera compartida por la mayoría de los futuros ciudadanos y, por lo tanto, capaz de potenciar la unidad y la convivencia pacífica.

Por otra parte, conocer la idea de España enseñada en nuestras Es- 
cuelas e Institutos, y considerar que esa idea pasa a formar parte del bagaje cultural e ideológico de los alumnos, tendría un interés limitado si pensáramos que una idea semejante apenas tiene fuerza para actuar sobre la realidad y que poco, o muy poco, puede influir en los comportamientos cívicos y políticos de los futuros ciudadanos. Porque lo cierto es que una idea de este tipo siempre es algo elemental y sencillo en su formulación, y se puede modificar varias veces a lo largo de la vida, si aceptamos que toda idea es producto de un razonamiento y todo razonamiento es susceptible de modificaciones.

Pero distinta sería la valoración si consideramos que las ideas aprendidas en la niñez y en la adolescencia con frecuencia acaban actuando más como creencias que como ideas. Sobre todo en aquéllos que no tienen la oportunidad posterior de recibir nuevas ideas que puedan modificar las anteriores. Porque las creencias pasan a formar parte de nuestro horizonte vital, arraigan en nuestra existencia con firmeza, se enlazan con nuestros actos de manera espontánea y se convierten en motores de nuestra actividad, en justificadores de nuestros pensamientos y en soporte de nuestra razón. Porque una idea o concepto que actúa como creencia tiene una influencia sobre nuestro comportamiento superior a la de cualquier idea «racional», adquirida mediante procesos analíticos o deductivos.

Un concepto aprendido en las etapas básicas de formación de la persona -como en este caso el concepto de España-por aquéllos para quienes lo aprendido en la Escuela o el Instituto va a constituir su principal o único bagaje educativo, al menos en ese aspecto concreto, actúa en ellos como una creencia. Y cuando se encuentren ante la necesidad de dar respuesta a la pregunta «¿qué es España?», y, en consecuencia, cuando tengan que adoptar posiciones y traducirlas en comportamientos, la creencia tiene por fuerza que influir considerablemente. Es decir, un concepto que una vez aprendido actúa como creencia es, sin duda, un «concepto operativo", por lo que un trabajo como el que proponemos también puede ser importante para explicar el comportamiento que los españoles han manifestado a lo largo de la historia, en relación con su idea de España. Sobre todo a la hora de definir los principios en los que han basado su convivencia, diseñar las distintas instituciones representativas y adoptar los diferentes modelos de Estado.

¿Hasta qué punto los comportamientos de los españoles en esas cuestiones han sido el resultado de unas ideas inculcadas en el proceso educativo a través de los libros de texto? Desde la constitución del Estado liberal, los sucesivos Gobiernos de muy diferentes situaciones políticas se han esforzado por transmitir determinadas ideas sobre la realidad de Es- 
paña. Lo han hecho porque consideraban que dichas ideas, convenientemente enseñadas, podían ser influyentes en el futuro para consolidar un concepto de España coherente con su ideología y sus intereses. Pensaban que los alumnos de hoy, ciudadanos políticamente activos del mañana, eran la mejor garantía para la defensa futura de esa ideología y de esos intereses. Lo mismo piensan hoy los que se muestran preocupados por este asunto y los que se afanan para no perder el control del sistema educativo, del que depende, entre otras muchas cosas, la enseñanza de un concepto tan importante para sus futuros intereses.

¿Han tenido éxito los sucesivos intentos de inculcar en la masa de la población un determinado concepto de España, mediante el sistema educativo y a través de los libros de texto? $O$, lo que es igual, ¿ha tenido éxito la Escuela en este cometido, en algún momento de los últimos doscientos años? Y, sobre todo, ¿obtendremos nosotros resultados semejantes?

Una rápida enumeración de las distintas situaciones políticas por las que ha pasado España en los últimos cien años puede aportarnos algunos datos de interés al respecto. Las teorías liberales impuestas -con todos los matices que se quiera- a lo largo del s. XIX, sobre la idea «unitaria» de España, no lograron evitar el éxito obtenido en algunas regiones por los movimientos regionalistas o abiertamente separatistas. Tampoco lograron evitar que un amplio sector de la población compartiera la visión negativa de nuestra Historia y las críticas formuladas por la Generación del 98 y los Regeneracionistas, críticas que, en buena medida, se referían precisamente a la visión de España que intentaban imponer los gobiernos liberales. La imposición en la enseñanza de un concepto de España «esencialista» y «tradicional», por obra de la Dictadura de Primo de Rivera, no parece que contribuyera demasiado a evitar el apoyo de una gran parte del pueblo a la II República, que impondría unas formas muy distintas de entender la realidad nacional. Tampoco las reformas educativas de la II República pudieron desarraigar de las masas conservadoras, tradicionales y católicas una idea de España que acabaría por imponerse en el Franquismo. Ni el largo periodo franquista, que impuso con obstinación un concepto de España "esencialista», católico, unitario y centralizado, que pretendía enlazar con la «España imperial» de los ss. XVI y XVII, pudo evitar el Estado laico configurado por la Constitución de 1978 y el «clamor autonomista» de la transición democrática, con la adopción de un «modelo de Estado» tan descentralizado, que a muchos empieza a parecerles un obstáculo serio para la futura unidad de España y, sobre todo, para la práctica futura de «algún tipo de patriotismo» que sustente la solidaridad entre las distintas Comunidades Autónomas, que haga posible nuestra convivencia pacífica y que nos permita emprender empresas comunes. 


\section{Javier Cermeño Aparicio}

A las Escuelas de Enseñanza Primaria y a los Institutos y Colegios de Secundaria se les encomendó, entre otros y variados cometidos, la misión de inculcar en las mentes de los futuros ciudadanos una idea de España que, actuando como creencia, sirviera para el desarrollo posterior de un patriotismo basado en el valor de la solidaridad y en el sentimiento del amor hacia la patria común de todos los españoles. Los libros de texto fueron el medio mayoritariamente utilizado para el logro de esos objetivos, considerados esenciales para el futuro del Estado español. Pero la proliferación -entre políticos, historiadores, educadores e intelectuales en general- de diferentes maneras de entender la realidad de España como nación, tenía por fuerza que manifestarse en la Escuela, el Instituto y el Colegio. Y lo hizo, dificultando la implantación de una idea dominante fruto del consenso. A cada nueva generación de españoles se les transmitió una idea de España diferente, cuando no contrapuesta, a la recibida por la generación anterior. Esto, en lugar de contribuir a facilitar la convivencia, contribuyó a que, entre nosotros, las rivalidades políticas en torno a los programas de gobierno tomaran la forma de enfrentamientos por el «modelo de Estado", que es tanto como decir, por la estructura estatal y, en definitiva, por la realidad y estructura de la misma nación.

El resultado de todo ello fue, con frecuencia, la debilidad del sentimiento patriótico de los españoles cuando el «modelo de Estado» adoptado no se avenía con sus expectativas o creencias. Y algo parecido podría afirmarse hoy: el enfrentamiento entre los defensores de una España autonómica, los que añoran una España «unitaria» y centralizada y los que desean configurar una España federal -por no mencionar a los que simplemente desean dejar de pertenecer a España-se traduce en unos bajos niveles del sentimiento patriótico en la mayoría de los españoles actuales. El recurso último a un "patriotismo constitucional» no parece ser la solución al problema.

Resumiendo lo dicho, se podría afirmar, en primer lugar, que la Escuela Primaria y el Instituto han influido en un número insuficiente de españoles, al menos hasta la segunda mitad del s. XX, por los reducidos niveles de escolarización alcanzados hasta entonces; en segundo lugar, que esa influencia ha sido -respecto a las ideas de España-tardía y en exceso errática; en tercer lugar, que a través del sistema escolar y mediante los libros de texto no se ha logrado consolidar una idea de España común y compartida por la mayoría de los españoles, aunque fuera en sus perfiles mínimos, en ningún momento de los últimos doscientos años; y en cuarto y último lugar, se podrá afirmar que a comienzos del s. XXI tenemos ante nosotros un problema de índole parecida al que se planteó 
en las primeras décadas del s. XIX, salvando todas las distancias y diferencias evidentes: qué idea de España debemos enseñar a nuestros alumnos de Primaria y de Secundaria, fruto del consenso necesario y suficiente, que sea capaz de contribuir a la convivencia solidaria, la unidad y la futura estabilidad de España como nación.

\section{Bibliografía}

CARo BAROJA, J. (1970): El mito del carácter nacional. Meditaciones a contrapelo. Madrid: Seminarios y Ediciones.

Fox, I. (1997): La invención de España. Madrid: Cátedra.

Gómez Molleda, Ma D. (1966): Los reformadores de la España Contemporánea. Madrid: C.S.I.C.

LAf́N EnTRAlgo, P. (1962): España como problema. Madrid: Aguilar.

Menéndez Pelayo, M. (1986): Historia de los Heterodoxos españoles. (2 vols.). Madrid: BAC. [ $1^{a}$ edición, 1880-1882].

SÁINZ RodRíguez, P. (1962): Evolución de las ideas sobre la decadencia española. Madrid: Rialp.

Santoveña SetiéN, A. (1994): Menéndez Pelayo y las derechas en España. Santander: Ayuntamiento de Santander y Ediciones de Librería Estudio. 